\title{
Prediction of Rock Strength using Drilling Data and Sonic Logs
}

\author{
Ali Amani \\ Petroleum University of Technology \\ Ahwaz, Iran
}

\author{
Khalil Shahbazi \\ Petroleum University of Technology \\ Ahwaz, Iran
}

\begin{abstract}
Uniaxial test (also called unconfined compression test) is one of most important tests used to measure rock strength. It is critical to obtain the rock strength parameters along the wellbore. Awareness of rock strength could better control drilling problems such as pipe sticking, tight hole, collapse, pack off and sand production. Rock strength also controls the drilling rate of penetration (ROP). The calculations of uniaxial Compressive Strength (UCS) are based on a simplified version of the ROP model proposed for tricone bits. The purpose of this research was to predict the uniaxial compressive strength based on sonic logs as a function of sonic travel and formation porosity. For obtaining continuous log strength along the wellbore in Ahwaz oilfield, quantitative relationships were developed between UCS and sonic travel time as well as UCS and both of sonic travel time and formation porosity. They actually are the outcome of regression analysis that resulting relationships are very practical and most often are specified by the researcher to the region of study. In this work, a larger well segment has been analyzed which there is no information break throughout the segment and it is investigated continuously. Using this approach, 3D model was a better predictor of uniaxial compressive strength than obtained equations related to transient time and results have also confirmed that the use of an recommended equations in this study can reduce drilling costs significantly.
\end{abstract}

\section{Keywords}

Uniaxial compressive strength; UCS; Sonic logs; Porosity; Prediction

\section{INTRODUCTION}

Uniaxial compressive strength (UCS) test is widely used for estimating the mechanical properties of rock material in rock engineering projects. In order to determine UCS, direct and indirect techniques are available. In the direct approach, UCS is determined from the laboratory UCS tests. In indirect techniques determine UCS is determined based on mathematical and empirical relationships. UCS is directly determined according to both the American Society for Testing and Materials (ASTM) [1], the International Society for Rock Mechanics (ISRM) [2] and other common standards. Rock mechanical laboratory testing on core samples are the most accurate methods for estimation of rock strength, but they never can lead to a continuous profile of rock strength along wellbore. Coring is very expensive and results are very sensitive to stress unloading [3]. Indirect methods are relatively simple and generally do not require any sample preparation. Due to the fact that standard experimental test methods based on established standards require costly equipment and that the methods for sample preparation is difficult and time-consuming, indirect methods are more favorable. In these methods, the UCS values are predicted with a simple mathematical model in a simpler, faster and more economical way.

Sonic travel time is one of the rock physical properties which mostly are used for reservoir evaluation and rock mechanical studies. It reflects the effect of lithology, porosity and fluid content. Neutron density log also can be used for driving rock strength from logs. Research has been focused on using them for rock property estimation in situations where there is limited or non-availability of core samples. Table 1 lists two empirical equations relating the strength of carbonate to measurable geophysical parameters. [4].

Table 1. Empirical relationships between UCS and petrophiscs logs in carbonate.

\begin{tabular}{|c|c|c|}
\hline No. & \multicolumn{1}{|c|}{ UCS $(\mathbf{M P a})$} & Reference \\
\hline$(1)$ & $\mathrm{UCS}=\left(\frac{7682}{\Delta \mathrm{t}}\right)^{1.82} / 145$ & $\begin{array}{c}\text { Militzer and } \\
\text { Stoll }(1973)\end{array}$ \\
\hline (2) & $\mathrm{UCS}=10^{(2.44+109.14 / \Delta \mathrm{t})} / 145$ & $\begin{array}{c}\text { Golubev and } \\
\text { Robinovich } \\
(1976)\end{array}$ \\
\hline
\end{tabular}

The use of drilling data to predict drilling rock strength has developed over a number of years as drilling models for various types of bits have steadily improved. Although penetration rate models have been proposed for polycrystalline diamond compact bits and natural diamond bits, the more traditional tricone roller bit has received the most attention because of its widespread use. To accomplish the objectives of this study, the drilling data from offset wells have been utilized to calculate the rock strength along the wellbore. Various equations exist that relate petrophysical properties of rocks to rock strength. The basis for these relations is the fact that many factors that affect rock strength also affect other physical properties of rocks. Although some of equations may work reasonably, rock strength variations with individual physical property measurements scatter considerably indicating that most of the empirical equations are not as accurate as they can fit all the data points from laboratory tests. As a matter of fact, because rocks of the same lithology have different characterization due to different composition and depositional environments, it is very hazardous to determine generic empirical equations for a rock type. Thus, most of the developed equations are presented for a specific region or rocks with specific characterization. This highlights the importance of local calibration for the equations before they are used to predict UCS for any stability analysis. 


\section{UCS CALCULATED FROM ROP MODELS}

Modeling of ROP has been attempted since the 1960's, but the models were not verified with laboratory data until the late 70's. The roller cone ROP performed by Amoco research developed the first two term model which linked WOB, RPM, bit size and rock strength [5]. Several ROP models have been developed and modified based on the concept where UCS is inversionally proportional with the rate of penetration. There are three most widely used models for estimating rate of penetration:

1. Modified Warren model (Tricone bit).

2. Drag bit model.

3. Burgoyne \& Young model

\subsection{Modified Warren Model}

A model of the drilling process for tricone bits called perfectcleaning model was derived by Warren and later modified by Hareland and Hoberok which is expressed as[5], [6]:

$\mathrm{ROP}=\mathrm{W}_{\mathrm{f}}\left(\mathrm{f}_{\mathrm{c}}\left(\mathrm{P}_{\mathrm{e}}\right)\left(\frac{\mathrm{aS}^{2} \mathrm{D}_{\mathrm{bit}}{ }^{3}}{\text { RPM.WOB }^{2}}+\frac{\mathrm{b}}{\text { RPM.D }_{\mathrm{bit}}}\right)+\frac{\mathrm{c} \rho \mu \mathrm{D}_{\mathrm{bit}}}{\mathrm{F}_{\mathrm{jm}}}\right)^{-1}$

Where ROP is drilling rate ( $\mathrm{ft} / \mathrm{hr}), \mathrm{S}$ is confined rock compressive strength (psi), $\mathrm{D}_{\text {bit }}$ is bit diameter (in), RPM is rotary speed (rev/min), WOB is weight on bit (Ibf), $\rho$ is mud density (ppg), $\mu$ is plastic viscosity (cp), $F_{j m}$ is modified impact force (Ibf), $\mathrm{f}_{\mathrm{c}}(\mathrm{Pe})$ is chip hold down function (dimensionless), $\mathrm{W}_{\mathrm{f}}$ is bit wear dimensionless factor and $\mathrm{a}, \mathrm{b}$ and $c$ are characteristic of the bit design. The first term of the equation defines the rate at which rock is broken into small chips by the bit. The second term modifies the predictions to account for the distribution of the applied weight on bit (WOB) to more teeth as the WOB increases and the teeth penetrate deeper into the rock. The third term accounts for the efficiency of the cutting removal process, based on hydraulics. As mentioned, $F_{j m}$ is modified impact force which is described in equation (4):

$\mathrm{F}_{\mathrm{jm}}=\left(1-\mathrm{A}_{\mathrm{v}}^{-0.122}\right) \times \mathrm{F}_{\mathrm{j}}$

Here $A_{v}$ is the ratio of the jet velocity to the fluid return velocity. Theoretically, the measured impact pressure should be independent of the nozzle size for a fixed bit size and a fixed value of the impact force calculated from Equation (5).

$\mathrm{F}_{\mathrm{j}}=0.000516 \rho q v_{\mathrm{n}}$

Where $V_{n}$ is nozzle velocity ( $\mathrm{ft} / \mathrm{sec}$ ) and $q$ is pump flow rate (gpm).

Chip hold down function estimates the resultant force on a chip generated by the bit can be calculated from below equation:

$f_{c}\left(P_{e}\right)=c_{c}+a_{c}\left(P_{e}-120\right)^{b_{c}}$

$\mathrm{P}_{\mathrm{e}}$ is effective differential pressure. It is actually the difference between pore pressure and circulation pressure at bottomhole. The $a_{c}, b_{c}$ and $c_{c}$ are lithology and permeability dependent parameters. Circulation pressure at bottom hole is summation of the static mud column pressure and annulus pressure drop. Circulation pressure at bottomhole is summation of the static mud column pressure and annulus pressure drop. This parameter can be calculated from equation (7).

$P_{E C D}=0.052 \rho T V D+\Delta P_{a n n}$

$\mathrm{P}_{\mathrm{ECD}}$ is in psi and TVD is true vertical depth in $\mathrm{ft}$.
When the section is drilled, the teeth of the rollercone bits start to wear and become dull. ROP will reduce when the dullness occurs. Teeth area increase is due to bit wear than reduce stress on each cutter. Hareland proposed below equation to calculate the bit wear:

$w_{f}=1-\frac{W_{c} \sum W O B_{i} \cdot R P M_{i} \cdot A_{a b r_{i}} \cdot S_{i}}{8}$

Here, $\Delta \mathrm{BG}$ is the change in bit tooth wear and $\mathrm{A}_{\text {abri }}$ is relative rock abrasiveness and $W_{c}$ is wear coefficient which is dimensionless.

Here $A_{a b r i}$ is relative rock abrasiveness and $W_{c}$ is wear coefficient which are dimensionless. For an offset well, all the above parameters are known except rock strength and bit wear characteristics. So, an inverted ROP model can provide a calibrated measurement of rock strength under actual drilling conditions and simultaneously determines wear characteristics of the bit which has been used to drill the relevant section [7] So, deliverable should be an apparent rock strength log (ARSL) along the wellbore attainable as below:

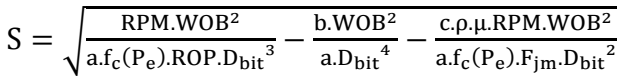

All of parameters are discussed before and other functions are described earlier. Since this model is combination of laboratory work and filed data, uncertainty in prediction of bit penetration rate will increase in high WOBs. [8], [9]

The rock strength calculated in the above equation is the rock strength, at the bit operating conditions, at the bottom of the hole. In ordinary drilling operations, the mud weight are higher than the pore pressure and the bit operates under confined conditions. Therefore, the rock strength calculated in the ROP models is the confined rock strength. To calculate the unconfined rock strength, a failure criterion is used as follow [10].

$\mathrm{UCS}=\frac{S}{\left(1+a_{s} \cdot p^{b_{s}}\right)}$

Here $a_{s}$ and $b_{s}$ are fitting constants for the failure criteria. Unconfined Compressive Strength Log (UCSL) is a representation of the apparent rock strength in a particular well or section, derived from the actual historical drilling data. To calculate the rock strength with the ROP models, as described above, drilling data, lithology information and bit data need to be known. After a well is drilled, all the information needed is available. In order to calculate apparent rock strength, the drilling data for a 6.125 inch section (Well A) in the Iranian south oilfield is given. Warren's model is illustrated in equation (3). Constants and relative multipliers are calculated using equations (4) to (8). Lithology plays an essential role in this model by introducing "S" (apparent rock strength) to the model. Thus, by reversing the model, "S" would be calculated (Equation (9)) and then according to permeability and lithology of the rock, the strength under drilling can be converted to uniaxial rock compressive strength (Equation (10)). Once all the input files and startup parameters were used in ROP model, strength profile can be obtained.

Figure 1 shows the UCSL from ROP models versus depth in well A. 


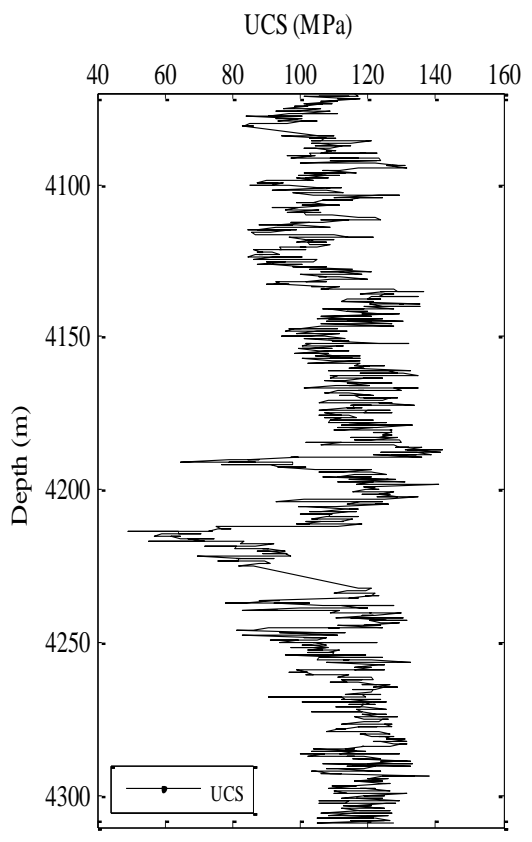

Fig1: UCSL from ROP in well A.

\section{PREDICTION OF UNAIXIAL COMPRESSIVE ROCK STRENGTH}

Rock strength data for carbonate rocks are collected from well A and statistical analysis is performed between sonic travel time and porosity to predict rock strength for near field area or all Ahwaz oil field by obtaining new relationships for rock strength. Limestone and dolomite rocks are categorized as carbonate rocks in this study. In the first step, probable relationship between parameters can be obtained by plotting rock strength among different petrophysical data.

\subsection{UCS and Sonic Travel Time}

Sonic travel time logging of boreholes is routinely used in oil industry to realize reservoir properties for more evaluation. However, we want to obtain reliable correlations between the unconfined compressive strength (UCS) and the sonic velocity. Figure 2 shows scatter plot from UCS versus sonic travel time.

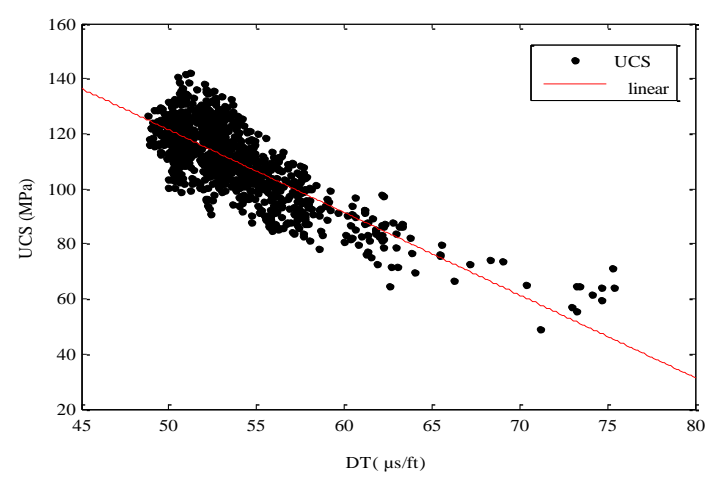

Fig 2: Behavior between sonic travel time versus UCS.

According to figure 2, probable relationship between UCS and sonic travel time is likely to be exponential, while linear, cubic and others are probable. For doing regression job, different models can be utilized and then regarding equation assessment markers, the best relationship can be picked up.
According to the statistical analysis, the largest $R^{2}{ }_{a d j}$ is 0.692 for exponential model and the largest F-value is 2491.412 that also related to the mentioned model. Furthermore, sigma is zero that means data are inconsistent and basic assumption for regression analysis is correct.

\subsubsection{Testing normality of residuals}

In a simple regression analysis, it is assumed that the distribution of residuals is, in the population, normal at every level of predicted $\mathrm{Y}$ and constant in variance across levels of predicted Y. If plotted standardized residuals among standardized predicted values do not fallow a distinct trend, these assumptions are acknowledged. The goal of a residual plot is to see a random scatter of residuals. Figure 3 shows the scatter plot related to exponential form of UCS- $\Delta \mathrm{t}$.

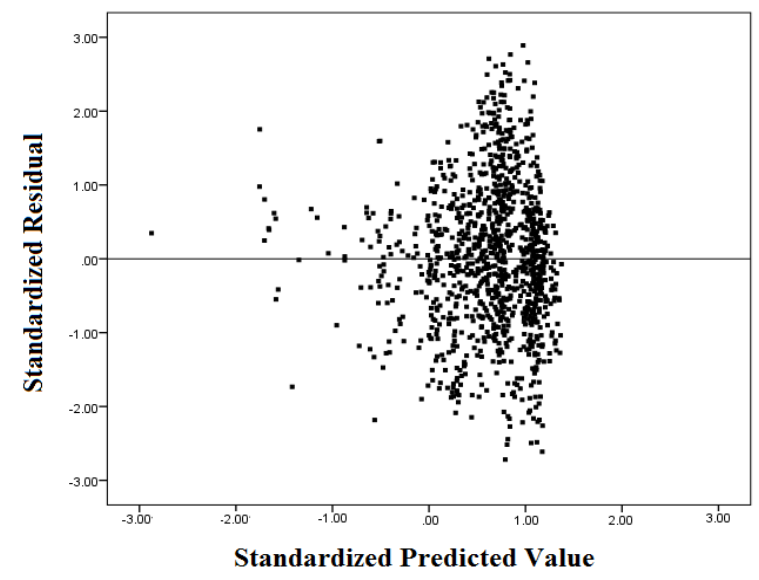

Fig 3: Scatter plot between standardized prediction and residual values of $\mathrm{UCS}$.

As you see there is no pattern in the residual plot, so assumptions are correct. Another assumption is normal distribution of the residuals. When number of data is greater than 30, regression can be done by assuming normal distribution of the residuals without any analysis. Figure 4 shows distribution of the standardized residuals which indicates normal distribution.

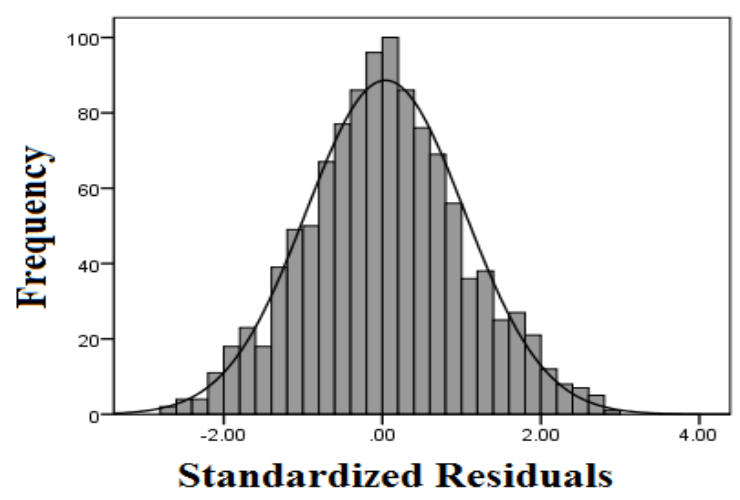

Fig 4: Normal distribution curve.

Thus, below equation can be used to predict rock strength in the carbonate formations:

$U C S=570.808 e^{-0.031 \Delta t}$

Here UCS is in $(\mathrm{MPa})$ and $\Delta \mathrm{t}$ is sonic travel time in $(\mu \mathrm{s} / \mathrm{ft})$. 


\subsection{UCS - Porosity - Sonic Travel Time}

Rock strength is resultant of contribution of rock properties such as grains texture, cement texture, porosity, fluid content and also degree of compaction. In order to reach more accuracy by employing the undeniable porosity roles in rock strength, it was decided to estimate UCS based on sonic travel time and porosity (NPHI logs). According to the statistical analysis, in this part multiple regressions have been used to recognize best relationship between UCS and porosity and sonic travel time. Thus, equation (7) was proposed for prediction of UCS based on the two physical properties of rock.

$U C S=194.4-0.6072 \Delta \mathrm{t}-646.1 \varnothing-0.01644 \Delta \mathrm{t}^{2}+$ 8.792( Ø. $\Delta t)$

Where, UCS is in MPa, $\Delta \mathrm{t}$ is sonic travel time in $(\mu \mathrm{s} / \mathrm{ft})$ and $\varnothing$ is porosity.

\section{VALIDATIN AND FIELD APPLICATION}

Different relationships are now derived to estimation of rock compressive strength in Carbonates of Ahwaz oilfield. Based on available data, well $\mathrm{B}$ was selected for validation of new derived relationships. Also here some of equations that was mentioned earlier are used to compare the result with other works. Figure 5 shows compare UCSL obtained from new derived equations with other relationships and laboratory UCS in well B.

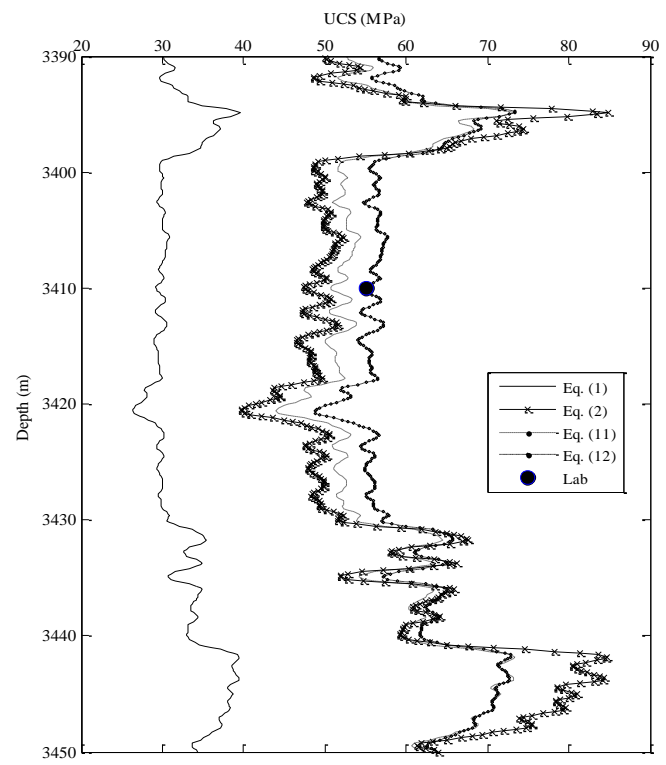

Fig 5: Comparing results with other equations and laboratory tests for well $B$.

As it is seen in figure 5, predicted UCS profile by new derived equations is very close to lab data. For this part, equation (1) and equation (2) are used, which both of them proposed to predict UCS for carbonate rock in various locations around the world. As it is obvious, equation (1) and equations (2) underestimated rock strength while equations (11) is very close to real data and equation (12) gives an excellent match with lab data.

\section{CONCLUSIONS}

The purpose of this research was to predict the uniaxial compressive strength based on sonic logs as a function of sonic travel and formation porosity.
For obtaining continuous log strength along the wellbore quantitative relationships were developed between UCS and sonic travel time as well as UCS and both of sonic travel time and formation porosity. They actually are the outcome of regression analysis that resulting relationships are very practical and most often are specified by the researcher to the region of study. Well segment length has a notable impact on precision and extension of obtained function. In this work, a larger well segment has been analyzed which there is no information break throughout the segment and it is investigated continuously.

Much theoretical work has been done to make the most accurate relationship to predict UCS in carbonate in Ahwaz oil field. Results have also confined that the 3D model was a better predictor of uniaxial compressive strength than obtained equation related to just transient time.

\section{REFERENCES}

[1] ASTM, 1986. Standard Test Method of Unconfined Compressive Strength of Intact Rock Core Specimens. ASTM Publication.

[2] ISRM, 2007. The Complete ISRM Suggested Methods for Rock Characterization. Testing and Monitoring: 1974-2006. International Society for Rock Mechanics, Commission on Testing Methods.

[3] Raaen, A. M., Hovem, K. A., Joranson, H. and Fjaer, E., 1996. FORMEL: A Step Forward in Strength Logging. In Proceedings of the SPE Annual Technical Conference and Exhibition, Denver, Colorado.

[4] Chang, C., Zoback, M. D. and Khaksar, A. 2006 Empirical relations between rock strength and physical properties in sedimentary rocks. Journal of Petroleum Science and Engineering, vol. 51, no. 3-4, pp. 223-237.

[5] T. Warren, 1987. Penetration Rate Performance of Roller Cone Bits. SPE Drilling Engineering, vol. Volume 2, pp. $9-18$.

[6] Hareland, G. and Hoberock, L. L. 1993. Use of Drilling Parameters to Predict In-Situ Stress Bounds. In Proceedings of the SPE/IADC Drilling Conference, Amsterdam, Netherlands.

[7] Rastegar, M., Hareland, G., Nygaard, R. and Bashari, A. 2008. Optimization of Multiple Bit Runs Based on ROP Models and Cost Equation: A New Methodology Applied for One of the Persian Gulf Carbonate Fields. In Proceedings of the IADC/SPE Asia Pacific Drilling Technology Conference and Exhibition, Jakarta, Indonesia.

[8] T. Warren. 1981. Drilling Model for soft-formation bits. Journal of Petroleum Technology, vol. Volume 33, pp. 963-970.

[9] Winters, W. J., Warren, T. M. and Onyia, E. C. 1987. Roller Bit Model With Rock Ductility and Cone Offset. In Proceedings of the SPE Annual Technical Conference and Exhibition, Dallas, Texas.

[10] Hareland, G. and Nygaard, R. 2007. Calculating Unconfined Rock Strength from Drilling Data. In Proceedings of the first Canada - U.S. Rock Mechanics Symposium, Vancouver, Canada. 